\title{
In vitro Evaluation of Mycobacterial Activity of Phytomedicine Mathesia on Mycobacterium tuberculosis
}

\section{Kabedi Bajani Marie Jose ${ }^{1 *}$, Kayembe Ntumba Jean Marie², Kashongwe Munogolo Zacharie2, Bisuta Fueza Serge ${ }^{2}$, Mampasi Kusangabo Philippe1, Mbaya Kalumba Paulin1, Taba Kalulu M³, Mifundu $\mathrm{MN}^{3}$, Mulenga Mbombo $\mathrm{C}^{3}$, Nkasa $\mathrm{HL}^{3}$, Tshitadi Makangu Augustin ${ }^{4}$, Nganga Nkanga Mireille ${ }^{1}$ and Muyembe Tamfum Jean Jacques ${ }^{1}$}

${ }^{1}$ Department of Medical Biology, Faculty of Medicine, University of Kinshasa, Democratic Republic of the Congo

${ }^{2}$ Department of Medicine Internal, Faculty of Medicine, University of Kinshasa, Democratic Republic of the Congo

${ }^{3}$ Department of Chemistry Organic, Faculty of Sciences, University of Kinshasa, Democratic Republic of the Congo

${ }^{4}$ Department of Public Health, Technical Medical Institute of Kinshasa, Democratic Republic of the Congo

*Corresponding author: Dr. Kabedi Bajani Marie Jose, Specialist of Department of Medical Biology, Faculty of Medicine, University of Kinshasa, Democratic Republic of the Congo, Tel: +00243998295595; E-mail: bedye2001@yahoo.fr

Received date: April 04, 2018; Accepted date: May 01, 2018; Published date: May 08, 2018

Citation: Jose KBM, Marie KNJ, Zacharie KM, Serge BF, Philippe MK, et al. (2018) In vitro Evaluation of Mycobacterial Activity of Phytomedicine Mathesia on Mycobacterium tuberculosis. Med Clin Rev Vol. 4 No. 2: 5.

Copyright: (C) 2018 Jose KBM, et al. This is an open-access article distributed under the terms of the Creative Commons Attribution License, which permits unrestricted use, distribution, and reproduction in any medium, provided the original author and source are credited.

\section{Abstract}

Introduction: At the international level, Directly Observed Treatment Short-Course (DOTS) is a public health strategy to effectively fight Tuberculosis (TB) epidemic. However, because of the irrational use of anti-tuberculosis drugs, Mycobacterium tuberculosis is developing more and more resistance to antibiotics and the number of cases of multidrug-resistant Tuberculosis (MR-TB and XDR-TB) is increasing. Thus, the therapeutic arsenal used in this context becomes limited and the care also becomes difficult.

Objective: The study aims to demonstrate in vitro efficacy of MATHESIA on Mycobacterium tuberculosis.

Methods: Thirty eight (38) positive Ziehl or Auramine sputum from failures and relapses cases were collected. After treatment with $4 \%$ sodium hydroxide, the direct method of proportion technique was used. It consisted of inoculating the pellets on Löwenstein-Jensen's medium (LJ), on incorporated LJ of MATHESIA at different concentrations and on LJ incorporated anti-tuberculosis drugs with well-known critical concentrations. The tubes were incubated at $37^{\circ} \mathrm{C}$ and read at 28 and 42 days for susceptibility testing.

Results: Six strains (15.8\%) were sensitive to all the antiTB drugs tested and also to MATHESIA. In contrast, 32 strains $(84.2 \%)$ were resistant to at least one antituberculosis drug. In contrast to MATHESIA, all the 32 strains resistant to at least one antituberculous drug showed growth only on a single concentration $(0.01$ $\mathrm{mg} / \mathrm{ml}$ ) whereas in the other 4 concentrations, growths were not observed, even for 21 MDR-TB souches (55.3\%).

Conclusion: The anti-mycobacterial activity is certain in the MATHESIA and more in-depth research must be done to determine its behavior in the treatment.

Keywords: Evaluation; In vitro; Activity; Mycobacterial; Phytomedicine; Mathesia; Mycobacterium tuberculosis.

\section{Introduction}

Tuberculosis is an infectious and contagious disease that poses a real public health problem in the world and in developing countries where at least $80 \%$ of the burden is found [1]. In 2013, the World Health Organization (WHO) estimated that 9 million people developed TB, 1.5 million died and more than $95 \%$ of cases and deaths occurred in developing countries [1].

In some areas heavily affected by TB, existing control strategies are overwhelmed by the increasing number of TB cases occurring in parallel with the HIV/AIDS pandemic [1,2]. Out of 9 million reported cases of TB in 2013, 0.4 millions are People Living with HIV (PLHIV) and 320,000 of the 1300000 dead are PLHIV [1].

Today, the burden of Multidrug-Resistant Tuberculosis (MDR-TB) is dramatically increasing worldwide, severely hampering the global fight against Tuberculosis (TB), which is traditionally based on early diagnosis, contact tracing, and appropriate treatment of cases of Pulmonary Tuberculosis [1-7]. MDR-TB is caused by bacilli resistant to at least the two 
most effective anti-tuberculosis drugs, isoniazid and rifampicin (MDR-TB).

WHO estimates at 480,000 , the number of MDR-TB in the world, $3.5 \%$ of new TB cases are MDR-TB and $20.5 \%$ of cases already treated are MDR-TB [1]. Approximately 9\% of MDR-TB patients are extensively resistant or in other words resistant to rifampicin and isoniazid as well as to fluoroquinolone and one of the aminoglycoside reserve drugs [1,3-9].

The Democratic Republic of Congo (DRC) is among the countries with the heavy burden of Tuberculosis and multidrug-resistant TB $[1,3,4]$. Its incidence rate of Tuberculosis is more than 300,000 per 100,000 inhabitants and the multidrug resistance is between 2000 and 19999 according to WHO estimates in 2013. The studies carried out in Kinshasa on primary resistance in 2007 and 2009, showed a resistance rate of $42.5 \%$ and a multi-resistance of $5.3 \%[3,4]$.

Currently, the DOTS strategy advocated by the World Health Organization contributes significantly to the fight against this scourge and helps slow the development and spread of drugresistant Tuberculosis bacilli [1-8]. The emergence of drugresistant TB bacilli complicates already-heavy treatment regimens and, in most poor countries, few can afford treatment for multidrug-resistant TB [4-8].

However, this treatment is complex, prolonged, expensive and requires appropriate infrastructure in the clinic and the laboratory. The majority of patients with MDR-TB still do not have access to adequate diagnostic services or quality secondline drugs [4-8]. This results in high rates of morbidity and mortality.

Thus, an urgent priority is to seek more effective and efficient MDR-TB treatments that can reduce toxicity and provide safe delivery to all patients, especially those coinfected with the HIV virus [1-3]. These solutions could lead to lower costs for health systems.

In this context, it is appropriate to undertake studies as recommended by the WHO in its 2014 report, to improve the treatment of MDR-TB, which has become a new emergency in order to identify the optimal combinations of drugs existing or new drugs to be combined into safe and effective, preferably short-lived, regimens that can be easily administered to patients and safely combined with antiretroviral therapy [1].

This study joins the above-mentioned WHO request to try to find other drugs or molecules to ensure better management of TB patients. It aims to demonstrate in vitro anti-mycobacterial activity of Mathesia, a phytomedicine, which seems to have a beneficial effect on Mycobacterium tuberculosis.

\section{Material and Methods}

\section{Type}

Prospective and experimental study was carried out from March 20 to June 30, 2014

\section{Place}

The study was conducted in Mycobacterial laboratory, Faculty of Medicine of the University of Kinshasa (UNIKIN).

\section{Study population}

Failure after treatment and relapses.

\section{Inclusion criteria}

Ziehl or Auramine positive patients giving informed consent.

\section{Exclusion criteria}

Patient Ziehl or Auramine negative and refusal to participate in the study.

\section{Collection of samples}

Sputums were collected in the following Tuberculosis Screening and Treatment Centers (CSDT) in Kinshasa: Elonga, Mother and Child Center of Ngaba, Saint Alphonse and the University Clinics of Kinshasa (CUK).

The Ziehl-Neelsen (ZN) and Auramine tests were performed for the detection of acid-fast bacilli (AFB) according to the recommendations of PATI IV and WHO [7,8]. The positive samples were transported to a cold storage tank and sent to the CUK Mycobacteria laboratory for culture, identification and susceptibility testing on the Löwenstein-Jensens (LJ) medium according to Canetti et al. [9].

These samples were processed by the Petroff method using $4 \%$ sodium hydroxide [9]. $0.2 \mathrm{ml}$ of pellets were seeded on pure Lowenstein-Jensen (LJ) media, incorporated LJ media of Mathesia at different concentrations (Table 1).

Table 1 Different concentrations of Mathesia and known concentration of antibacterial agents.

\begin{tabular}{|c|c|c|c|c|c|c|}
\hline \multirow{3}{*}{$\begin{array}{l}\text { Medium } \\
\text { Pure } \\
\text { Lowenstein- } \\
\text { Jensens }\end{array}$} & \multirow{2}{*}{$\begin{array}{l}\text { Anti-tuberculosis } \\
\text { agent }(\mu \mathrm{g})\end{array}$} & \multicolumn{5}{|c|}{ Concentration $(\mu \mathrm{g} / \mathrm{ml})$} \\
\hline & & - & - & - & - & - \\
\hline & Isoniazide (I) & 0.2 & - & - & - & - \\
\hline & Rifampicine (R) & 40 & - & - & - & - \\
\hline & Ethanbutol $(E)$ & 2 & - & - & - & - \\
\hline & Streptomycine (S) & 4 & - & - & - & - \\
\hline & Ofloxacine (O) & 4 & - & - & - & - \\
\hline & Kanamycine $(\mathrm{K})$ & 30 & - & - & - & - \\
\hline & Mathesia & 10 & 30 & 50 & 100 & 125 \\
\hline
\end{tabular}

2 thiophene carboxylic acid ( $\mathrm{TCH})$ was used for biochemical identification of strains [9]. The direct method of the proportion technique of Canetti et al. was used. It consists of inoculation directly on pure media, anti-tuberculosis media and Mathesia, treated Ziehl or Auramine positive samples [9]. 
The cultures were incubated at $37^{\circ} \mathrm{C}$ and observed $24-72$ hours later to look for signs of contamination. Readings were performed at the 28th and 42nd day of incubation [9].

Mathesia was obtained from the Industrial and Technological Group (GITCO), Kinshasa, DR Congo. It is a hydroalcoholic solution of plant extracts containing the following secondary metabolites: saponins, polyphenols tannins and reducing sugars.

\section{Data processing}

The data was entered on the Excel software and transferred to the $\mathrm{R}$ software for analysis. The significance threshold was set at $5 \%$.

\section{Results}

At the end of this study, $38 \mathrm{M}$. Tuberculosis strains were isolated from 38 patients included. These strains came from 32 cases of failures and 6 cases of relapses.
The distribution of samples by site shows that 21 samples (55.3\%) from CDST Saint Alphonse; 10 (26.3\%) from CSDT Elonga; 5 (13.2\%) from University Clinics of Kinshasa (CUK) and 2 (5.2\%) from Mother and Children Center of Ngaba.

The average age of all patients was 34 years with extremes ranging from 14 to 74 years. The majority of patients (75\%) were in the 15 to 45 age group.

The distribution by sex shows that $13.2 \%$ (5) were women and $86.8 \%$ (33) were men. The difference was significant $(P=0.000)$. The susceptibility of the strains to antituberculous drugs and Mathesia is shown in Table 2.

Table 2 indicates that 6 strains (15.8\%) were sensitive to all the anti-tuberculosis drugs tested and Mathesia extracts at all the concentrations used, namely: $0.01 ; 0.03 ; 0.05 ; 0.1$ and $0.125 \mathrm{mg} / \mathrm{ml}$. In contrast, 32 strains $(84.2 \%)$ were resistant to at least one anti-tuberculosis drug and a concentration of Mathesia extracts $(0.01 \mathrm{mg} / \mathrm{ml})$.

Table 2 Sensitivity Tuberculosis strains against Mathesia and anti-tuberculosis.

Note: R: Rifampicin; H: Isoniazid; S: Streptomycin; E: Ethambutol; O: Ofloxacin; K: Kanamycin; S: Sensible; R: Resistant.

\begin{tabular}{|c|c|c|c|c|c|c|c|c|c|c|c|c|}
\hline \multirow{2}{*}{$\begin{array}{l}\mathrm{N}^{\circ}- \\
\text { Samples }\end{array}$} & \multicolumn{4}{|c|}{ Different dilutions of Mathesia } & \multicolumn{8}{|c|}{ Anti-tuberculosis at critical concentration } \\
\hline & $100 \mathrm{~g}$ & $30 \mathrm{ug}$ & $50 \mu \mathrm{g}$ & $\begin{array}{l}100 \\
\mathrm{ug} / \mathrm{ml}\end{array}$ & $125 u$ & $\begin{array}{l}\mathrm{H}: 0.2 \\
\mathrm{ug} / \mathrm{ml}\end{array}$ & $\begin{array}{l}\mathrm{R}: 40 \\
\mathrm{ug} / \mathrm{ml}\end{array}$ & $\begin{array}{l}\mathrm{E}: 2 \\
\mathrm{ug} / \mathrm{ml}\end{array}$ & $\begin{array}{l}\mathrm{S}: 4 \\
\mathrm{ug} / \mathrm{ml}\end{array}$ & O: $4 \mathrm{ug} / \mathrm{ml}$ & $\mathrm{K}: 30 \mathrm{ug} / \mathrm{ml}$ & $\mathrm{T}: 2 \mathrm{ug} / \mathrm{ml}$ \\
\hline 1 & $\mathrm{R}$ & s & s & $\mathrm{s}$ & s & $\mathrm{R}$ & $\mathrm{R}$ & $\mathrm{R}$ & $\mathrm{R}$ & s & s & $\mathrm{R}$ \\
\hline 2 & $\mathrm{R}$ & S & s & $S$ & S & $\mathrm{R}$ & $\mathrm{R}$ & $\mathrm{s}$ & S & s & S & $\mathrm{R}$ \\
\hline 3 & $\mathrm{R}$ & S & s & $S$ & S & s & $\mathrm{R}$ & S & $\mathrm{R}$ & $\mathrm{R}$ & S & $\mathrm{R}$ \\
\hline 4 & $\mathrm{R}$ & S & s & $\mathrm{s}$ & S & $\mathrm{R}$ & $\mathrm{R}$ & $\mathrm{R}$ & $\mathrm{R}$ & S & $\mathrm{s}$ & $\mathrm{R}$ \\
\hline 5 & $\mathrm{R}$ & $S$ & $S$ & $S$ & $S$ & $S$ & $\mathrm{R}$ & S & $S$ & S & s & $\mathrm{R}$ \\
\hline 6 & $\mathrm{R}$ & $S$ & $S$ & S & s & $S$ & $\mathrm{R}$ & S & S & S & s & $\mathrm{R}$ \\
\hline 7 & $\mathrm{R}$ & $S$ & $S$ & $S$ & $S$ & $\mathrm{R}$ & $\mathrm{R}$ & $\mathrm{R}$ & $\mathrm{R}$ & S & S & $\mathrm{R}$ \\
\hline 8 & $\mathrm{R}$ & $S$ & $S$ & $S$ & $S$ & $\mathrm{R}$ & $\mathrm{R}$ & $\mathrm{R}$ & $\mathrm{R}$ & $S$ & $S$ & $\mathrm{R}$ \\
\hline 9 & $\mathrm{R}$ & $S$ & $S$ & $S$ & $S$ & $\mathrm{R}$ & $\mathrm{R}$ & $\mathrm{R}$ & $\mathrm{R}$ & $\mathrm{s}$ & $R$ & $\mathrm{R}$ \\
\hline 10 & $\mathrm{R}$ & $S$ & $S$ & $S$ & $S$ & $S$ & $\mathrm{R}$ & $S$ & $\mathrm{R}$ & $\mathrm{R}$ & $\mathrm{s}$ & $\mathrm{R}$ \\
\hline 11 & $S$ & $S$ & $S$ & $S$ & $S$ & $S$ & $S$ & $S$ & $\mathrm{~S}$ & $S$ & $S$ & $\mathrm{R}$ \\
\hline 12 & $\mathrm{R}$ & $S$ & $S$ & $S$ & S & $\mathrm{R}$ & $\mathrm{R}$ & $\mathrm{R}$ & $R$ & $S$ & $\mathrm{~S}$ & $\mathrm{R}$ \\
\hline 13 & $\mathrm{R}$ & $S$ & $S$ & $S$ & $S$ & $S$ & $S$ & $\mathrm{R}$ & $R$ & $R$ & S & $\mathrm{R}$ \\
\hline 14 & $\mathrm{R}$ & $S$ & $S$ & $S$ & $S$ & $S$ & $S$ & $\mathrm{R}$ & $R$ & $S$ & $S$ & $\mathrm{R}$ \\
\hline 15 & $\mathrm{R}$ & $S$ & $S$ & $S$ & $\mathrm{~s}$ & $S$ & $S$ & $S$ & $R$ & $\mathrm{~s}$ & S & $\mathrm{R}$ \\
\hline 16 & $\mathrm{R}$ & S & $S$ & $S$ & S & $\mathrm{R}$ & $\mathrm{R}$ & $S$ & S & S & $S$ & $\mathrm{R}$ \\
\hline 17 & $\mathrm{R}$ & S & $S$ & $\mathrm{~s}$ & s & $\mathrm{R}$ & $S$ & $S$ & $S$ & $S$ & $s$ & $\mathrm{R}$ \\
\hline 18 & $\mathrm{R}$ & $\mathrm{s}$ & $S$ & $S$ & $\mathrm{~s}$ & $\mathrm{R}$ & $\mathrm{R}$ & $S$ & $R$ & S & $\mathrm{s}$ & $\mathrm{R}$ \\
\hline 19 & $\mathrm{R}$ & $S$ & $S$ & $S$ & S & $\mathrm{R}$ & $\mathrm{R}$ & $S$ & $R$ & $S$ & S & $\mathrm{R}$ \\
\hline 20 & $S$ & $S$ & $S$ & $S$ & $S$ & $S$ & $S$ & $S$ & $S$ & $S$ & $\mathrm{~s}$ & $\mathrm{R}$ \\
\hline 21 & $\mathrm{R}$ & $S$ & $S$ & S & $S$ & $S$ & $\mathrm{R}$ & S & $S$ & $S$ & $R$ & $\mathrm{R}$ \\
\hline
\end{tabular}




\begin{tabular}{|c|c|c|c|c|c|c|c|c|c|c|c|c|}
\hline 22 & $\mathrm{R}$ & $S$ & $S$ & $S$ & $S$ & $\mathrm{R}$ & $R$ & $S$ & $S$ & $\mathrm{R}$ & $s$ & $\mathrm{R}$ \\
\hline 23 & $\mathrm{R}$ & $S$ & $S$ & $S$ & $S$ & $S$ & $S$ & $S$ & $\mathrm{R}$ & $S$ & $R$ & $\mathrm{R}$ \\
\hline 24 & $\mathrm{R}$ & $S$ & $S$ & $S$ & $S$ & $R$ & $R$ & $\mathrm{R}$ & $S$ & $S$ & $S$ & $\mathrm{R}$ \\
\hline 25 & $\mathrm{R}$ & $S$ & $S$ & $\mathrm{~S}$ & $S$ & $R$ & $R$ & $\mathrm{R}$ & $S$ & $S$ & $S$ & $\mathrm{R}$ \\
\hline 26 & $\mathrm{R}$ & $S$ & S & $\mathrm{s}$ & $S$ & $\mathrm{R}$ & $\mathrm{R}$ & $\mathrm{s}$ & $\mathrm{s}$ & $S$ & S & $\mathrm{R}$ \\
\hline 27 & $\mathrm{R}$ & $S$ & $S$ & $S$ & $S$ & $\mathrm{R}$ & $\mathrm{R}$ & $\mathrm{R}$ & $S$ & $S$ & $\mathrm{R}$ & $\mathrm{R}$ \\
\hline 28 & $\mathrm{R}$ & $S$ & $S$ & $\mathrm{~s}$ & $S$ & $\mathrm{R}$ & $\mathrm{R}$ & $S$ & $\mathrm{~s}$ & $S$ & $\mathrm{R}$ & $\mathrm{R}$ \\
\hline 29 & $\mathrm{R}$ & $S$ & $S$ & $\mathrm{~s}$ & $S$ & $\mathrm{R}$ & $\mathrm{R}$ & $S$ & $\mathrm{R}$ & $S$ & $S$ & $\mathrm{R}$ \\
\hline 30 & $\mathrm{R}$ & S & $\mathrm{S}$ & $\mathrm{s}$ & $S$ & $\mathrm{R}$ & $R$ & $\mathrm{R}$ & $\mathrm{s}$ & $S$ & S & $\mathrm{R}$ \\
\hline 31 & $S$ & $S$ & S & $S$ & $S$ & $S$ & $S$ & $S$ & S & $S$ & S & $\mathrm{R}$ \\
\hline 32 & $S$ & $S$ & $\mathrm{~s}$ & S & $S$ & $\mathrm{~S}$ & S & $\mathrm{s}$ & $\mathrm{s}$ & $S$ & S & $\mathrm{R}$ \\
\hline 33 & $S$ & $S$ & $\mathrm{~s}$ & $S$ & $S$ & $S$ & $S$ & S & $\mathrm{s}$ & $S$ & $S$ & $\mathrm{R}$ \\
\hline 34 & $\mathrm{R}$ & $S$ & $S$ & $S$ & $S$ & $\mathrm{R}$ & $\mathrm{R}$ & $\mathrm{R}$ & $S$ & $S$ & $\mathrm{R}$ & $\mathrm{R}$ \\
\hline 35 & $\mathrm{R}$ & $S$ & $S$ & $S$ & $S$ & $\mathrm{R}$ & $\mathrm{R}$ & $\mathrm{R}$ & $S$ & $S$ & $S$ & $\mathrm{R}$ \\
\hline 36 & $S$ & $S$ & $S$ & $S$ & $S$ & $S$ & $S$ & $S$ & $S$ & $S$ & $S$ & $\mathrm{R}$ \\
\hline 37 & $\mathrm{R}$ & $S$ & S & $S$ & $S$ & $R$ & $\mathrm{R}$ & $\mathrm{R}$ & $\mathrm{R}$ & $S$ & $S$ & $\mathrm{R}$ \\
\hline 38 & $\mathrm{R}$ & $S$ & $S$ & $S$ & $S$ & $S$ & $S$ & $S$ & $S$ & $\mathrm{R}$ & $\mathrm{R}$ & $\mathrm{R}$ \\
\hline
\end{tabular}

The prevalence of TB drug resistance is shown in Table 3.

Table 3 Rate of resistance of anti-tuberculosis ( $\mathrm{n}$ : nombre de souches).

\begin{tabular}{|l|l|l|}
\hline Anti-tuberculosis & $\mathbf{n}$ & $\%$ \\
\hline Isoniazid & 22 & 57.9 \\
\hline Rifampicin & 26 & 68.4 \\
\hline Ethambutol & 15 & 39.5 \\
\hline Streptomycin & 16 & 42.1 \\
\hline Ofloxacin & 9 & 23.7 \\
\hline Kanamycin & 9 & 23,7 \\
\hline
\end{tabular}

Table 3 illustrates that resistance of rifampicin (68.4\%) was the leading, followed by Isoniazid (57.9\%), streptomycin (42.1\%) and Ethambutol (39.5\%). Resistance to Kanamycin and Ofloxacin was similar (23.7\%). Multidrug Resistance (MR-TB) that is resistance to both Isoniazid and Rifampicin is shown in Figure 1.

Figure 1 shows that $55.3 \%$ of strains were multi-resistant while $44.7 \%$ were not. We found $10.5 \%$ of Pre-ultra-resistant strains.

\section{Discussion}

Man always resorts to plants and seeks remedies from the latter to cure infections of the organism $[10,11]$.

The discovery of antibiotics has revolutionized the field of infectious diseases and these antibiotics have saved a very large number of lives to the point that infectious diseases could one day be curbed [12]. Unfortunately, the phenomenon of resistance has appeared making certain antibiotics ineffective.

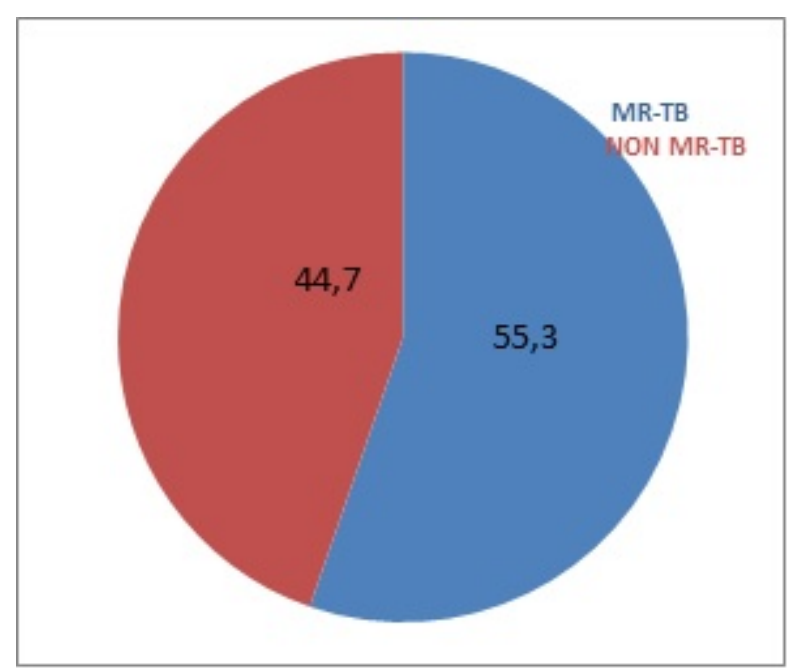

Figure 1 MDR-TB (\%).

In the vast majority of cases, the use of antibiotics leads to the selection of resistant microbial populations, and in the same way the unreasoned use of anti-tuberculosis leads to the emergence of resistant strains of Mycobacterium tuberculosis.

This drug resistance is at the origin of the high cost of patient care and the lack of sufficient financial means limits population to buy pharmaceutical products with the 
consequence of desertion or late attendance of medical facilities [10-12]. This is why most people find herbal medicine as an alternative to medication.

Most African countries are trying to remedy this situation by demonstrating a renewed interest in traditional medicine because drug problems in these countries arise in terms of economic inaccessibility, qualitative and quantitative insufficiency [10-12]. Hence, WHO has advocated the use of traditional pharmacopoeia and the participation of all traditional practitioners in developing primary health care [12].

Several earlier studies have been carried out to determine new antimicrobial agents that are effective than synthetic drugs and well accepted by the body without deleterious effects on human health [13-17].

Thus, a lot of research carried out in the world on plants, allowed to determine the antimicrobial activity of medicinal plants extracts such as fennel (Foeniculum vulgare), peppermint (Mentha piperita), thyme (Thymus vulgaris), Cogniauxia podolaena etc. [10-17].

Researchers had shown that extracts are active not only against bacteria but also against fungi, yeasts and viruses [13-19].

Other groups of researchers have taken a more important step in isolating and identifying the metabolites responsible of antimicrobial activity of plant extracts. This stage provides a platform for many implications including pharmaceutical industries, alternative medicine and natural therapy $[18,19]$.

The importance and effectiveness of traditional pharmacopoeia are not to be demonstrated, but its systematic use in the hospital remains a problem with multiple polemics because there are several charlatans in this area.

However, the major problem is to convince the population to use traditional recipes in case of health discomfort. This is why we recommend that scientific studies be carried out on any traditional medicinal recipe.

With this in mind, we conducted this study, which aimed to determine the anti-mycobacterial activity of the phytomedicine Mathesia. Thirty-eight strains were isolated from patients in a state of failures and relapses because another study in progress recruited only these cases and this enabled us to objectify the behavior of strains of Mycobacterium tuberculosis vis-a-vis Mathesia. From the 38 strains of $M$. Tuberculosis tested, 6 strains (15.8\%) were sensitive to all tested anti-tuberculosis drugs and Mathesia extracts at all concentrations used, namely: $0.01 ; 0.03 ; 0.05$; 0.1 and $0.125 \mathrm{mg} / \mathrm{ml}$. In contrast, 32 strains (84.2\%) were resistant to at least one anti-tuberculosis drug and also to one concentration of Mathesia extract $(0.01 \mathrm{mg} / \mathrm{ml})$.

The distribution by sex and age shows that the male sex predominated and the difference was significant $(P=0.000)$. The preponderance of the male sex observed in this study ( 86.8 vs. $13.2 \%$ ) is in agreement with some authors who claim that women tend to consult less frequently than men health care facilities in our African circle, because of certain sociocultural barriers $[20,21]$.

The majority of our patients were in the 15 to 45 age group. This result corroborates that of WHO, which shows that the same age group is most affected by Tuberculosis [1-4]. This age group is composed of active and highly mobile population.

Kouassi et al. 's study (Cote d'Ivoire 2004) shows predominance in the age group of 20 to 45 years and it is the male sex that was more concerned. These are young adults, the most economically productive, encountered in the various sectors of activity [22]. Six strains (15.8\%) of M. Tuberculosis were sensitive to all the anti-TB drugs tested and Mathesia. This result shows that Mathesia's contribution to the fight against Tuberculosis and it seems interesting to deepen the data in order to demonstrate the beneficial effects of Mathesia in Tuberculosis patients.

The approach is supported by the work of Maghrani et al. who report that medicinal plants represent a significant source of new drugs; especially since they have fewer side effects [23].

This hypothesis is also supported by the work of Rojas et al. which show that the antimicrobial potency of plant extracts depend on their chemical compositions and these plants contain many compounds with an antimicrobial action such as phenolic compounds, flavonoids, essential oils and triterpenoids [19]. This is the case of the phytomedicine Mathesia that we have evaluated its anti-mycobacterial activity.

The present study reports that 32 strains (84.2\%) were resistant to at least one anti-TB drug as indicated in Table 1. This result shows that there is a real public health problem that can reverse current TB control efforts [1]

In contrast to Mathesia, all 32 strains resistant to at least one antituberculous, showed growth only on a single concentration $(0.01 \mathrm{mg} / \mathrm{ml})$, the other 4 concentrations, did not show growths, even for the 21 souches (55.3\%) MR-TB as shown in Table 1.

In other words, the 32 strains were sensitive at 4 concentrations, except one $(0.01 \mathrm{mg} / \mathrm{ml})$. This shows that Mathesia can make a considerable contribution in the management of Tuberculosis patients. This result suggests the need for a deep assessment of the extent and limits of Mathesia's sensitivity to $M$. Tuberculosis in order to draw good conclusions.

The study reports a very high Tuberculosis resistance rate as shown in Table 2 . Other studies have reported similar finding: as the case of Sangare et al. and Thapa et al. who also have shown significantly higher individual resistance in previously treated patients. The high rates reported in this survey can be explained by the category (II and IV) of patients included, the smallness of the sample and the prescription of certain molecules in other pathologies. Isoniazid, which is prescribed for prevention, can also select resistant mutants [24,25]. 
For MDR-TB, the study reports a rate of $55.3 \%$ as shown in Figure 1. Compared with the results of other surveys, the proportion is lower than those reported by Kouassi et al. and Hamid Salim et al. in category I and II failed patients (79\% vs. $90 \%)$. On the other hand, it is higher than those described by Thapa et al. and Adane et al. (19.4\% vs. $16.67 \%)$ [26,27]. The high rate of MDR-TB, found in our series, may be probably due to the fact that the study focused on patients in a state of therapeutic failure and relapse. The difference in rates can be explained by the sample size, methodology used and prevalence of MDR-TB in each country.

The proportion of $10.5 \%$ of preXDR-TB observed in this survey is less than that $(49.4 \%)$ reported by Singhal et al. in India [28].

Isolated MDR-TB and preXDR-TB strains pose a real threat to $T B$ control as these strains circulate in the community with the risk of contamination.

Although the study showed the contribution of Mathesia in the fight against Tuberculosis, it also has a limit that of the smallness of the sample size because the smaller the sample size, the more the chance plays on certain parameters.

\section{Conclusion}

The anti-mycobacterial activity is certain in MATHESIA and further research is needed to evaluate the extent and limits of its sensitivity in order to draw definitive conclusions.

\section{References}

1. World Health Organization (2014) Global Tuberculosis Report.

2. Programme des Nations Unies pour le developpement (2006) Lutte contre le Sida, la Tuberculose et le paludisme. Rapport des activites. PNUD/Fonds Mondial.

3. Kabedi MJ, Kayembe JM, Kabengele B, Kashongwe Z, Bola V, et al. (2009) Profil et evolution de la resistance Primaire de Mycobacteriumtuberculosis aux antituberculeux dans deux centres de traitement à Kinshasa. Ann Afr Med 2: 129-134.

4. Kabedi MJ, Kashongwe M, Kayembe JM, Mumba D, Mampasi $P$, et al. (2007) Resistance primaire de Mycobacteriumtuberculosis aux antituberculeux à Kinshasa. Bull Soc Pathol Exot 100 275-276.

5. Programme national de lutte contre la Tuberculose (2008) Programme antituberculeux integre aux soins de sante de base, 4ème edition (PATI 4). PNT/RDC.

6. Partnership ST (2006) The global plan to Stop TB, 2006-2015, actions for life: Towards a world free of Tuberculosis. Int J Tuberc Lung Dis 10: 240-241.

7. World Health Organization (2007) The Global MDR-TB and XDRTB Response Plan 2007-2008.

8. World Health Organization. Standard operating procedure for Auramine staining, Module 27.

9. Canetti G, Froman F, Grosset J, Hauduroy P, Langerova M, et al. (1963) Mycobacteria: Laboratory methods for testing drug sensitivity and resistance. Bull World Health Organ 29: 565-578.
10. Abjanohoun EJ, Ahyi NRA, Akeassi L, Akpagana K, Chibon P, et al. (1986) Medecine traditionnelle et pharmacopee. Contribution aux etudes Ethnobotanique et floristique au Togo. A.C.C.T 627.

11. Abjanohoun EJ, Ahyi NRA, Akeassi L, Akpagana K, Chibon P, et al. (1989) Medecine traditionnelle et pharmacopee. Contribution aux etudes Ethnobotanique et floristique en Republique Populaire de Benin, A.C.C.T 885.

12. OMS (1978) Importance des medicaments essentiels et des plantes medicales. Chronique OMS 32: 294-296.

13. Tamfum M, Kadima Nzuji M (1980) Activite antibacterienne d'une preparation traditionelle de Cogniauxia podolaena. Medecine de l'Afrique Noire 27: 551-555.

14. Garcia-Ruiz A, Bartolome B, Martinez-Rodriguez AJ, Pueyo E, Martin-Alvarez PJ, et al. (2008) Potential of phenolic compounds for controlling lactic acid bacteria growth in wine. Food Control 19: 835-841.

15. N'Dukwe KC, Okeke IN, Lamikanra A, Adesina SA, Aboderin O (2005) Antibacterial activity of aqueous extracts of selected chewing sticks. J Contempor Dent Practic 6: 86-94.

16. Mustofa, Valentin A, Benoit-Vical F, Pelissier Y, Kone-Bamba D, et al. (2000) Antiplasmodial activity of plant extracts used in West African traditional medicines. J Ethnopharmacol 73: 145-151.

17. Reichling J, Schnitzler P, Suschke U, Saller R (2009) Essential oils of aromatic plants with antibacterial, antifungal, antiviral, and cytotoxic properties: An overview. Forsch Komplement Med 16: 79-90.

18. Guangrong H, Jiaxin J, Dehui D (2008) Antioxidative and antibacterial activity of the methanol extract of Artemisia anomala S. Moore. Afric J Biotechnol 7: 1335-1338.

19. Rojas A, Hernandez L, Pereda-Miranda R, Mata R (1992) Screening for antimicrobial activity of crude drug extracts and pure natural products from Mexican medicinal plants. J Ethnopharmacol 35: 275-283.

20. Salim MAH, Declercq E, Van Deun A, Saki KAR (2004) Differences entre sexes en matière de tuberculose: une enquête de prevalence menee au Bengladesh. Int J Tuberc Lung Dis 8: 952-957.

21. Crampin AC, Glynn JR, Floyd S, Malema SS, Mwinnuka VK, et al. (2004) Tuberculose en fonction du sexe: Exploration des types de la maladie dans une etude cas-contrôle au Malawi. Int J Tuberc Lung Dis 8: 194-203.

22. Kouassi B, Horo K, N'douba KA, Koffi N, Ngom A, et al. (2004) epidemiologique et microbiologique des malades tuberculeux en situation d'echec ou de rechute à Abidjan. Bull Soc Pathol Exot 97: 336-337.

23. Sangare L, Diande S, Kouanda S, Dingtoumda BI, Mourfou A, et al. (2010) Mycobacterium tuberculosis drug-resistance in previously treated patients in Ouagadougou, Burkina Faso. Ann Afr Med 9:15-19.

24. Thapa G, Pantalon ND, Khatiwada S, Lekhak B, Shrestha B (2016) Drug susceptibility patterns of the Mycobacterium tuberculosis isolated from previously treated and new cases of pulmonary Tuberculosis at German-Nepal Tuberculosis project laboratory, Kathmandu, Nepal. Antimicrob Resist Infect Control 5: 30.

25. Maghrani M, Zeggwagh N, Michel J, Eddoules M (2005) Antihypertensive effect of Lepidium sativum $L$. in spontaeneously hypertension rats. I Ethnopharmacol 100: 193-197. 
26. Salim MAH, Aung KJM, Hossain MA, Van Deun A (2006) Diagnostic microscopique precoce et rapide des vrais echecs de traitement et de la MDR-TB. Int J Tuberc Lung Dis 10:1248-1254.

27. Adane K, Ameni G, Bekele S, Abebe M, Aseffa A (2015) Prevalence and drug resistance profile of Mycobacterium tuberculosis isolated from pulmonary Tuberculosis patients attending two public hospitals in East Gojjam zone, northwest Ethiopia. BMC Public Health 15: 572.

28. Singhal P, Dixit P, Singh P, Jaiswal I, Singh M, et al. (2016) A study on pre-XDR and XDR Tuberculosis and their prevalent genotypes in clinical isolates of Mycobacterium tuberculosis in north India. Indian J Med Res 143: 341-347. 